\title{
Genetic basis of some physiological traits and their association with yield in pre-breeding germplasm of bread wheat (Triticum aestivm L.)
}

Mian Abdur Rehman Arif ( $\nabla$ m.a.rehman.arif@gmail.com )

Nuclear Institute for Agriculture and Biology (NIAB) https://orcid.org/0000-0002-8247-9558

Muhammad Imran

Nuclear Institute for Agriculture and Biology (NIAB), Jhang Road, Faisalabad

Muhammad Qandeel Waheed

Nuclear Institute for Agriculture and Biology (NIAB), Jhang Road, Faisalabad

Anjuman Arif

Nuclear Institute for Agriculture and Biology (NIAB), Jhang Road, Faisalabad

Sukhwinder Singh

Geneshifters, 222 Mary Jena Lane 255, Pullman

\section{Sajid Shokat}

Nuclear Institute for Agriculture and Biology (NIAB), Jhang Road, Faisalabad

\section{Short Report}

Keywords: Association mapping, BreadWheat, Pre-breeding germplasm, Physiological traits, Biplot

Posted Date: March 4th, 2021

DOl: https://doi.org/10.21203/rs.3.rs-277729/v1

License: (c) (i) This work is licensed under a Creative Commons Attribution 4.0 International License.

Read Full License 


\title{
Genetic basis of some physiological traits and their association with yield in pre-breeding germplasm of bread wheat (Triticum aestivm L.)
}

\author{
Mian Abdur Rehman Arif ${ }^{1 *}$, Maryam ${ }^{1}$, Muhammad Imran², Muhammad Qandeel Waheed ${ }^{1}$, Anjuman Arif ${ }^{1}$ \\ Sukhwinder Singh ${ }^{3}$, Sajid Shokat ${ }^{1}$ \\ ${ }^{1}$ Wheat Breeding Group, Plant Breeding and Genetics Division, Nuclear Institute for Agriculture and Biology, Jhang \\ Road, Faisalabad, Pakistan \\ ${ }^{2}$ Saline Agriculture Group, Soil and Environmental Sciences Division, Nuclear Institute for Agriculture and Biology, \\ Jhang Road, Faisalabad, Pakistan \\ ${ }^{2}$ Geneshifters, 222 Mary Jena Lane, Pullman, WA 99163, USA \\ *Correspondence: (Mian Abdur Rehman Arif), m.a.rehman@gmail.com
}

\section{Abstract}

The rise in human population necessitates the use of all available tools to enhance wheat productivity. In this regard, pre-breeding has mobilized novel under-utilized genetic variation into breeding programs. However, this germplasm needs to be characterized for its efficient utlization. This investigation was initiated to evaluate the early and late sown wheat pre-breeding germplasm for physiology and yield related traits and to associate the mapped SNPs using association mapping approach. Our results indicate that the germplasm performed better in early sowing in comparison to late planting where grain yield $(\mathrm{Yd})$ was found positively correlated with water use efficiency (WUE), heading time and chlorophyll contents (Chl). We discovered a total of 210 associations involving 155 SNPs. Taking into consideration either early or late sowing and the mean values only 12 markers traits were involved with germination, plant height, stomatal conductance, transpiration rate, Chl, carotenoids and Yd. Our correlations and mapping results indicate that higher WUE along-with Chl can be targeted as indirect physiological markers to enhance wheat yield.

Keywords Association mapping . BreadWheat . Pre-breeding germplasm. Physiological traits. Biplot

\section{$\underline{\text { Introduction }}$}

Wheat (Triticum aestivum L.) is the most important crop of the world as global food security heavily relies on it (Curtis and Halford, 2014). A decreasing trend has been observed in global wheat production from last few years owing to multiple factors (FAO 2019). The gravity of the situation is also evident from the fact that until 2050, 9 billion global inhabitants will be served from the same produce. Therefore, current wheat production should be doubled to meet the growing demand by 2050 (Ray et al. 2013).

According to a recent estimate, Pakistan stands $8^{\text {th }}$ in terms of area and 29th in terms of wheat yield per unit area (Hassan et al., 2020). The rise in human population necessitates plant breeders to utilize and adopt all available tools to enhance wheat productivity on a sustainable basis (Curtis and Halford, 2014).

Pre-breeding is playing a pivotal role by mobilizing novel under-utilized genetic variation into breeding programs through introducing less undesired linked genes (Moore 2015). In this regard, Seeds of Discovery (SeeD) project at CIMMYT has resulted in the creation of new pre-breeding germplasm with a view to enhance the use of genetic resources in breeding programs (Singh et al. 2018). The same germplasm has been used to track loci linked to yield-related traits (Akram et al. 2020), nematode resistance (Dababat et al. 2021), karnal bunt (Singh et al. 2020) and terminal drought stress (Shokat et al. 2020a). However, determining the genetic basis of physiological traits has not been attempted so far. Therefore, this investigation was initiated to associate the SNPs with some physiological traits and yield ( $\mathrm{Yd}$ ) in early as well as late sowings of wheat pre-breeding germplasm using association mapping approach.

\section{Materials and methods}

The current study was conducted on 118 hexaploid wheat pre-breeding lines derived from vast germplasm of CIMMYT (Singh et al. 2018). Table S1 provides the pedigree of this germplasm along with genotypic ID. Two plant 
experiments were conducted side by side under field conditions; early $\left(24^{\text {th }}\right.$ Oct, 2017) and late planting experiment $\left(24^{\text {th }}\right.$ Nov, 2017). During field preparation nitrogen $(N)$, phosphorous $\left(\mathrm{P}_{2} \mathrm{O}_{5}\right)$ and potash $\left(\mathrm{K}_{2} \mathrm{O}\right)$ were applied at the rate of 60,90 and $60 \mathrm{~kg} \mathrm{ha}^{-1}$, respectively. Seeds were sown manually at the rate of $5 \mathrm{~g}$ seeds for 2 meters rows which were $22.5 \mathrm{~cm}$ apart. At each of tillering and booting growth stage, $\mathrm{N}$ was also applied at $30 \mathrm{~kg}$ $\mathrm{ha}^{-1}$. The plants were irrigated 5 times, while the first irrigation was given after four weeks of sowing. All other agronomic and plant protections measures were practiced up to crop maturity.

In total, data regarding 12 morphological and physiological traits were recorded. These included germination \% (Gr); recorded three weeks after sowing according to a scale ranging from $0-100 \%$, where $0 \%=$ no germination and $100 \%=$ complete germination, heading time $(\mathrm{Hd})$; measured when $50 \%$ of spikes have emerged from the flag leaf, plant height $(\mathrm{Ht})$; recorded in $\mathrm{cm}$ from 5 random plants per replicate through meter rod from the base of plant to spike tip excluding awns, transpiration rate (Tr); calculated using the hand held porometer (Model: LI-1600 steady state porometer) in $\mu \mathrm{g} \mathrm{cm}^{-2} \mathrm{~s}^{-1}$, stomatal conductance (Sc); in $\mathrm{mmol} \mathrm{m}^{-2} \mathrm{~s}^{-1}$ using the formula: 1/DR $\times$ CF, where DR is diffusible resistance calculated from porometer, $\mathrm{CF}=$ correction factor calculated using the formula: LT $\mathrm{x}$ constant (411.8), and leaf temperature (LT) calculated from porometer, photosynthetic rate (Phr); determined from Sc and $\mathrm{Tr}$ of three randomly selected flag leaves per genotype using the formula: $\mathrm{Phr}=\mathrm{Sc}\left(\mathrm{mmol} \mathrm{m} \mathrm{sec}^{-2} / \mathrm{Tr}\left(\mu \mathrm{g} \mathrm{cm}^{-2} \mathrm{~s}^{-1}\right) \mathrm{x}\right.$ 10 , water use efficiency (WUE) was calculated by dividing the corresponding photosynthetic rate with transpiration rate times 100 . Sc, Tr and Phr were recorded separately on sunny days at the time of heading in respective sowings between 11:00 am and 2:00 pm and yield (Yd); recorded after manual threshing in grams per genotype.

Furthermore, same flag leaf samples used for measuring Sc, Tr and Phr were collected from each genotype to measure pigments (chlorophyll and carotenoids). Fresh leaf samples were chopped ( $0.5 \mathrm{~g}$ fresh weight) and extracted with $20 \mathrm{~mL} 80 \%$ acetone $(V / V)$. After the addition of acetone to chopped leaf samples glass tubes were placed at $10^{\circ} \mathrm{C}$ in dark until complete color disappeared. Afterward, samples were centrifuged at $14000 \times \mathrm{g}$ for 5 minutes and absorbance of supernatants was measured at 645,652, 663 and $480 \mathrm{~nm}$ on spectrophotometer (Hitachi-2800) according to Arnon (1949) and Davies and Taylor (1976). From the absorbance readings, chlorophyll a, chlorophyll b, total chlorophyll and carotenoids were calculated using following formula;

Chlorophyll a $($ Chla $)=\frac{[12.7(O D 663)-2.69(O D 645)] \times V}{1000 \times W}$
Chlorphyll b $($ Chlb $)=\frac{[22.9(O D 645)-4.68(O D 663)] \times V}{1000 \times W}$
Total Chlorophyll $($ ChlT $)=\frac{[20.2(O D 645)-8.02(O D 663)] \times V}{1000 \times W}$

Where $\mathrm{V}$ is the volume of sample extract $(\mathrm{mL}), \mathrm{OD}$ is the optical density and $\mathrm{W}$ is the weight of fresh tissue.

Caroenoids (Car) $=\frac{A^{\text {car }}}{E_{\max } 100}$

Where $A^{\text {car }}=(O D 480)+0.114(0 D 663)-0.638(O D 645)$ and $E_{\max } 100=2500$

All statistical analyses of phenotypic data including descriptive statistics and visualization (phenotypic histograms, biplot construction and correlation plot) were carried out in RStudio-1.0.153 software. Individual traits measured in early and late sowing and their mean were used to find the marker traits associations (MTAs) associated with traits under study employing freely available software, TASSEL v5.2.43 (Bradbury et al., 2007). The genotypic data consisting of 7,180 high quality SNPs obtained from Singh et al. (2018) employing PCA matrix (PC=3) coupled with the K-matrix, both of which were generated through TASSEL v5.2.43. SNPs that gave a $p$-value of $0.001(-\log 10$ value of 3 ) for a given trait were claimed as significant association.

\section{$\underline{\text { Results and discussion }}$}

All the measured traits of the wheat germplasm exhibited continuous variation (Fig. 1 and Fig S1-S11). Higher values recorded in early sowing provide evidence that late sowing showed a negative effect on all the traits except Gr (Table S2). Interestingly, Phr was similar in both sowing times. Superior performance in early sowing over late sowing could be due to prolonged growing season ( 2 weeks) beside other advantages as early flowering in late sowing caused early $\mathrm{Hd}$ (Table S2) that reduced the assimilates time to mobilize and contribute to plant development and ultimately yield (Rehman-Arif et al. 2020; Bennett et al. 2012). 
In order to explore the link of $Y d$ with other traits, combined correlation of both early and late sowing data was performed (Fig S12) which indicated that Yd was positively correlated with WUE $\left(r^{2}=0.25\right), \mathrm{Hd}\left(r^{2}=0.21\right)$, Chla $\left(r^{2}=\right.$ 0.17), Chlb $\left(r^{2}=0.13\right)$ and ChIT $\left(r^{2}=0.15\right)$. Furthermore, a biplot (Fig 2) using PCA was constructed to get latent relationship among the observed traits. As evident from Fig 1, Yd was very close to WUE confirming the results of correlation analysis. Previous reports indicate that higher Phr helps plants to maintain optimum grain yield as well as adaptability (Shokat et al., 2020b, 2021). In the current study, Phr was clustered closer to WUE and Yd (Fig.2) indicating maintenance of $\mathrm{Yd}$ could be due to higher WUE and Phr. It is further suggested that these two parameters can be used as physiological markers to enhance $\mathrm{Yd}$ of wheat. However, further in depth investigations are required to explain the hidden mechanism Yd in relation to of WUE.

Association analysis identified a total of 210 associations involving 155 SNPs on all wheat chromosomes except chromosomes 4D and 7D (Table S3). Taking into consideration either early or late sowing and the mean values, only 12 markers were identified that were linked with $\operatorname{Gr}$ ( $M 7873$ on chromosome $1 B$ at $103.58 \mathrm{cM}, \mathrm{R}^{2}=0.10-0.11$ ), $\mathrm{Ht}$ (M9057 (on chromosome 2B at $165.39 \mathrm{cM}$ ), M4664 and M3592 (on chromosome 5B at 102.15 and $209.79 \mathrm{cM}$, $\left.\mathrm{R}^{2}=0.12-0.14\right)$, $\mathrm{Sc}$ and $\operatorname{Tr}\left(M 2654\right.$ on chromosome 3B at $\left.81.47 \mathrm{cM}, \mathrm{R}^{2}=0.11-0.13\right)$, Chla (M8777 on chromosome 1B at $114.75 \mathrm{cM}, \mathrm{R}^{2}=0.14-0.17$ ), Chlb (M12 on chromosome 6A at $97.09 \mathrm{cM}, \mathrm{R}^{2}=0.12-0.15$ ), ChlT (M9193 on chromosome $1 \mathrm{~B}$ at $167.58 \mathrm{cM}, \mathrm{R}^{2}=0.10-0.11$ ), $\mathrm{Car}$ ( $\mathrm{M} 6457$ (on chromosome $2 \mathrm{~A}$ at $242.24 \mathrm{cM}$ ) and M4336 (on chromosome 2D at 270.96), $R^{2}=0.11-0.14$ ) and $Y d(M 7113$ and $M 5797$ (on chromosome 1B) at 230.06 and 241.77 $\left.\mathrm{cM}, \mathrm{R}^{2}=0.11-0.13\right)$. Using the same criteria, no MTA was discovered for $\mathrm{Hd}$, Phr and WUE. Rehman Arif et al. (2020) have reported chromosome $1 B$ as carrier of Gr QTLs in NIAB field conditions. Likewise, chromosome 2B is reported to carry Ht MTAs by Akram et al. (2020) at 147-158 cM. Furthermore, chromosome 1B has been focused by Akram et al. (2020) regarding Yd in another set of PBLs. On the other hand, MTAs linked with Chl and other physiological traits do not match with previous reports (Colasuonno et al. 2017; Panio et al. 2013; Zhang et al. 2009) suggesting that a wide range of variation exists in the PBLs with respect to these traits and more investigations are needed to find stable associations across wide range of environments.

Plant growth depends on photosynthesis (Czyczyło-Mysza et al. 2013) and the higher Phr could improve plant output (Shokat et al. 2020b, 2021). ChIT is a trait that can be used as a reliable indicator for photosystem PSII efficiency (Vijayalakshmi et al. 2010). Flag leaf Chl contents at flowering time have been reported to be positively associated with yield in wheat (Quarrie et al. 2006) which supports our finding. Likewise, Car contents are essential for photosynthetic process and in photoprotection of photosynthetic membranes against the large amounts of solar energy absorbed by photosynthetic pigments (Asada 1999). However, our analysis showed no association of Car contents with $\mathrm{Yd}$ yet, in biplot, both $\mathrm{Yd}$ and Car were going in the same direction. Perhaps Car contents contributed towards $Y d$ but clear mechanism is unknown.

It is concluded that a wide variety of loci in the germplasm are regulating important morpho-physiological traits in wheat. In addition, WUE and Phr can be targeted as indirect markers of selection to enhance grain yield.

Author's contribution Mian Abdur Rehman Arif conceived the idea and designed the study. Maryam, Muhammad Imran and Muhammad Qandeel Waheed performed the experiments. Sukhwinder Singh and Sajid Shokat performed the analysis. Mian Abdur Rehman Arif wrote the manuscript. Sukhwinder Singh, Muhamamd Imran, Sajid Shokat and Anjuman Arif reviewed the manuscript. All authors read and approve the final manuscript.

\section{Compliance with ethical standards}

Conflict of interest Ethical approval
The authors declare that they have no conflict of interest.

This article does not contain any studies with animals or humans performed by any of the authors.

\section{$\underline{\text { References }}$}


Akram S, Rehman-Arif MA, Hameed A (2020) A GBS-based GWAS analysis of adaptability and yield traits in bread wheat (Triticum aestivum L.). J Appl Genet 62:27-41

Arnon D (1949) Estimation of total chlorophyll. Plant Physiol 24:1-15

Asada K (1999) The water-water cycle in chloroplasts: scavenging of active oxygens and dissipation of excess photons. Ann Rev Plant Biol 50:601-639

Bennett D, Reynolds M, Mullan D, Izanloo A, Kuchel H, Langridge P, Schnurbusch T (2012) Detection of two major grain yield QTL in bread wheat (Triticum aestivum L.) under heat, drought and high yield potential environments. Theor Appl Genet 125:1473-1485

Bradbury PJ, Zhang Z, Kroon DE, Casstevens TM, Ramdoss Y, Buckler ES (2007) TASSEL: software for association mapping of complex traits in diverse samples. Bioinformatics 23:2633-2635

Colasuonno P, Lozito ML, Marcotuli I, Nigro D, Giancaspro A, Mangini G, De Vita P, Mastrangelo A M, Pecchioni N, Houston K (2017) The carotenoid biosynthetic and catabolic genes in wheat and their association with yellow pigments. BMC Genomics 18:1-18

Curtis T, Halford N (2014) Food security: the challenge of increasing wheat yield and the importance of not compromising food safety. Ann Appl Biol 164:354-372

Czyczyło-Mysza I, Tyrka M, Marcińska I, Skrzypek E, Karbarz M, Dziurka M, Hura T, Dziurka K,Quarrie S (2013) Quantitative trait loci for leaf chlorophyll fluorescence parameters, chlorophyll and carotenoid contents in relation to biomass and yield in bread wheat and their chromosome deletion bin assignments. Mol Breed 32:189-210

Dababat A, Rehman-Arif MA, Toktay H, Atiya O, Shokat S, Gul E, Imren M, Singh SA (2021) GWAS to identify the cereal cyst nematode (Heterodera filipjevi) resistance loci in diverse wheat prebreeding lines. J Appl Genet 62:93-98

Davies BH, Taylor RF (1976) Carotenoid biosynthesis-the early steps. Carotenoids-4: 211-221

FAO (2019). Food and Agriculture Organization of the United Nations. Rome, Italy. Available online. http://www.fao.org/worldfoodsituation/csdb/en/. Accessed 21 Sept 2020

Hassan R, Waheed MQ, Shokat S, Rehman-Arif MA, Tariq R, Arif M, Arif A (2020) Estimation of genomic diversity using sequence related amplified polymorphism (SRAP) markers in a mini core collection of wheat germplasm from Pakistan. Cereal Res Commun 48:33-44

Moore $G$ (2015). Strategic pre-breeding for wheat improvement. Nat Plants 1:1-3

Panio G, Motzo R, Mastrangelo A, Marone D, Cattivelli L, Giunta F, De Vita P (2013) Molecular mapping of stomatal-conductance-related traits in durum wheat (Triticum turgidum ssp. durum). Ann Appl Biol 162:258-270

Quarrie S, Pekic Quarrie S, Radosevic R, Rancic D, Kaminska A, Barnes J, Leverington M, Ceoloni C, Dodig $D$ (2006) Dissecting a wheat QTL for yield present in a range of environments: from the QTL to candidate genes. J Exp Bot 57:2627-2637

Ray DK, Mueller ND, West PC, Foley JA (2013) Yield trends are insufficient to double global crop production by 2050. PloS one 8: e66428

Rehman-Arif MA, Attaria F, Shokat S, Akram A, Waheed MQ, Arif A, Börner A (2020) Mapping of QTLs associated with yield and yield related traits in durum wheat (Triticum durum Desf.) under irrigated and drought conditions. Int J Mol Sci 21:2372

Shokat S, Großkinsky DK, Liu, F (2021) Impact of elevated $\mathrm{CO}_{2}$ on two contrasting wheat genotypes exposed to intermediate drought stress at anthesis. J Agron Crop Sci. 207: 20-33

Shokat S, Sehgal D, Vikram P, Liu F, Singh S (2020a) Molecular markers associated with agrophysiological traits under terminal drought conditions in bread Wheat. Int J Mol Sci 21:3156

Shokat S, Großkinsky DK, Roitsch T, Liu F (2020b) Activities of leaf and spike carbohydrate-metabolic and antioxidant enzymes are linked with yield performance in three spring wheat genotypes grown under well-watered and drought conditions. BMC Plant Biol 20:400 
Singh S. et al (2018) Harnessing genetic potential of wheat germplasm banks through impact-orientedprebreeding for future food and nutritional security. Sci Rep 8:12527

Singh S, Sehgal D, Kumar S, Rehman-Arif MA, Vikram P, Sansaloni CP, Fuentes Dávila G, Ortiz C (2020) GWAS revealed a novel resistance locus on chromosome 4D for the quarantine disease Karnal bunt in diverse wheat pre-breeding germplasm. Sci Rep 10:1-11

Vijayalakshmi K, Fritz AK, Paulsen GM, Bai G, Pandravada S, Gill BS (2010) Modeling and mapping QTL for senescence-related traits in winter wheat under high temperature. Mol Breed 26:163-175

Zhang K, Zhang Y, Chen G, Tian J (2009) Genetic analysis of grain yield and leaf chlorophyll content in common wheat. Cereal Res Commun 37:499-511

\section{List of Figures}

Fig 1 Frequency distribution of yield (a), QQ-plot (b) and manhattan plots in early (E) and late (L) planting and mean (M) of two experiments (c)

Fig 2 Biplot from combined principle component analysis

\section{List of Tables}

\section{List of Supplementary Figures}

Fig S1 Frequency distribution of Gr (a), QQ-plot (b) and manhattan plots in early (E) and late (L) sowing and mean (M) of two experiments (c)

Fig S2 Frequency distribution of Hd (a), QQ-plot (b) and manhattan plots in early (E) and late (L) sowing and mean (M) of two experiments (c)

Fig S3 Frequency distribution of $\mathrm{Ht}(\mathrm{a}), \mathrm{QQ}-$ plot (b) and manhattan plots in early (E) and late (L) sowing and mean (M) of two experiments (c)

Fig S4 Frequency distribution of $\operatorname{Tr}(\mathrm{a})$, QQ-plot (b) and manhattan plots in early (E) and late (L) sowing and mean (M) of two experiments (c)

Fig S5 Frequency distribution of Sc (a), QQ-plot (b) and manhattan plots in early (E) and late (L) sowing and mean (M) of two experiments (c)

Fig S6 Frequency distribution of Phr (a), QQ-plot (b) and manhattan plots in early (E) and late (L) sowing and mean (M) of two experiments (c)

Fig S7 Frequency distribution of Wue (a), QQ-plot (b) and manhattan plots in early (E) and late (L) sowing and mean (M) of two experiments (c)

Fig S8 Frequency distribution of Chla (a), QQ-plot (b) and manhattan plots in early (E) and late (L) sowing and mean (M) of two experiments (c)

Fig S9 Frequency distribution of Chlb (a), QQ-plot (b) and manhattan plots in early (E) and late (L) sowing and mean (M) of two experiments (c)

Fig S10 Frequency distribution of ChIT (a), QQ-plot (b) and manhattan plots in early (E) and late (L) sowing and mean (M) of two experiments (c)

Fig S11 Frequency distribution of Car (a), QQ-plot (b) and manhattan plots in early (E) and late (L) sowing and mean (M) of two experiments (c)

Fig S12 Combined correlation plot of 12 measured traits in the germplasm

\section{List of Supplementary Tables}

Table S1 Serial number, germplasm ID and pedigree of the germplasm

Table S2 Range, mean, variance, kurtosis, skewness and confidence level of various traits observed in the germplasm in early (E) or late (L) sowing and mean (M) of two treatments 
Table S3 Marker trait associations detected with MLM for various traits at $p$-value $<0.001$. Markers that were significant in either of the treatments and mean are in bold 
Figures

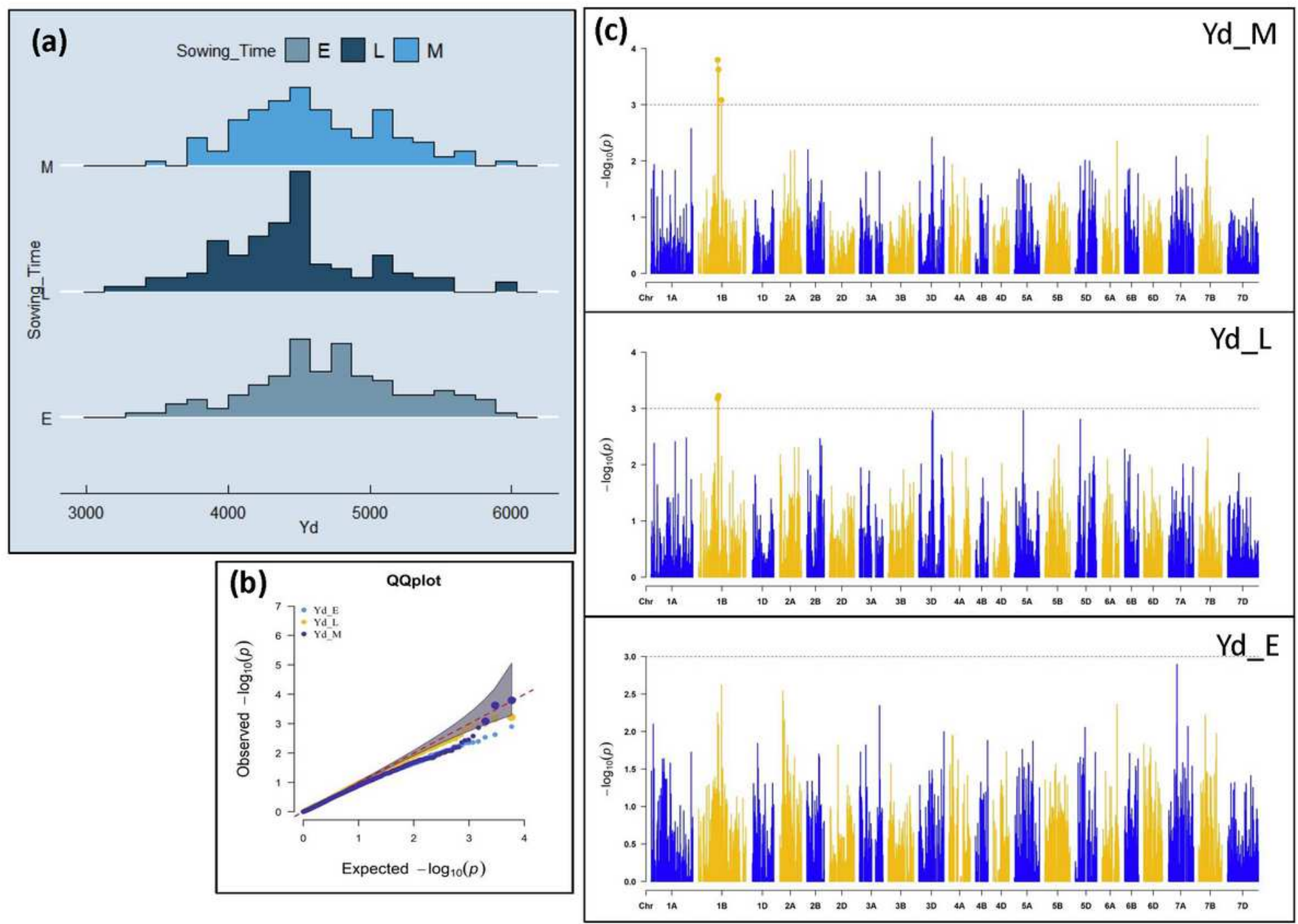

Figure 1

Frequency distribution of yield (a), QQ-plot (b) and manhattan plots in early (E) and late (L) planting and mean (M) of two experiments (c) 


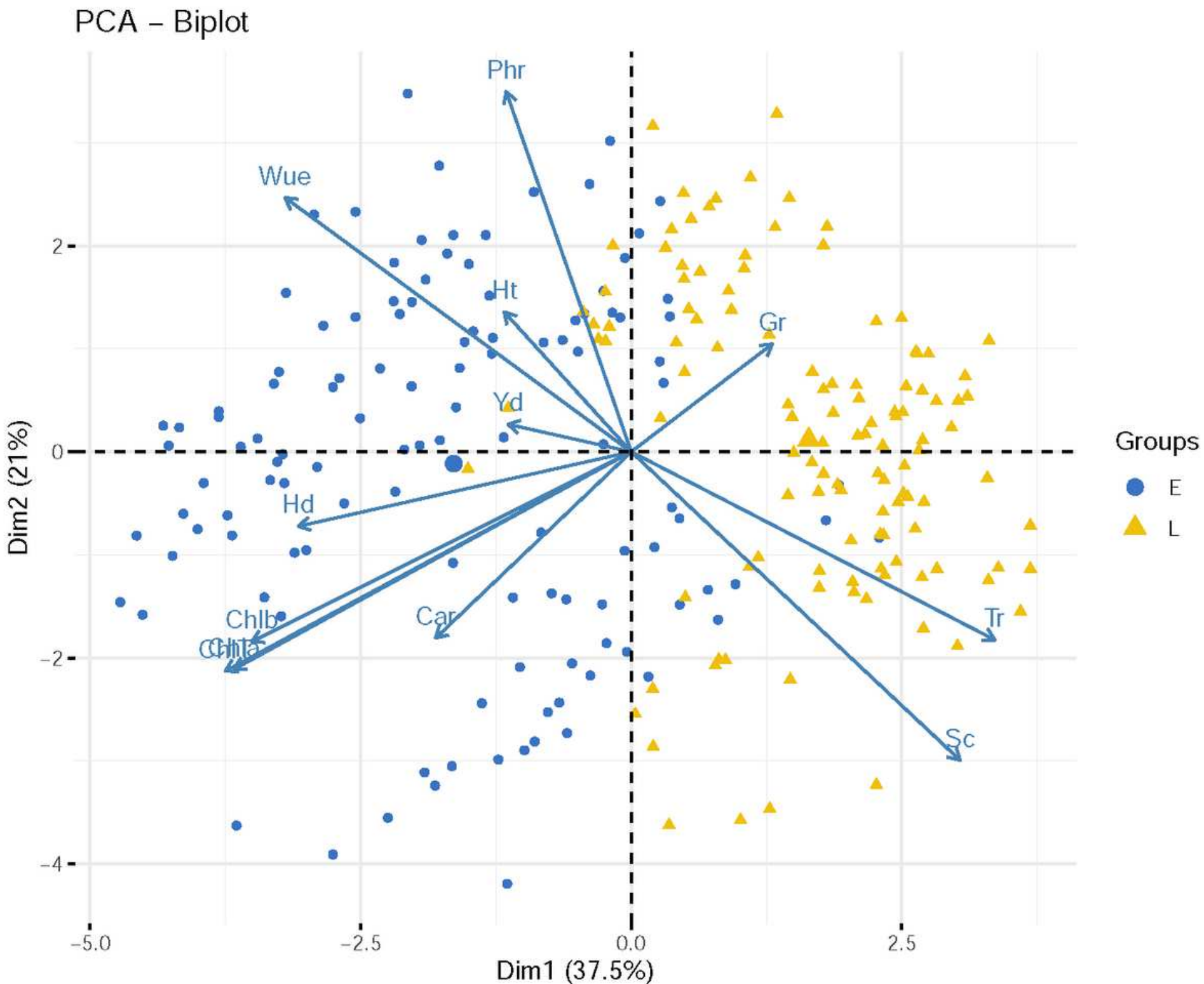

Figure 2

Biplot from combined principle component analysis

\section{Supplementary Files}

This is a list of supplementary files associated with this preprint. Click to download.

- FigS1toS11.pdf

- Figs12.pdf

- TableS1S2S3.xlsx 